\title{
Perceived quality of clinical Care provided by nurses to people living with HIV at Four TASO sites in Uganda
}

Kenneth Mugisha ${ }^{1,2^{*}}$, Coutinho Alex ${ }^{2}$

From $16^{\text {th }}$ International Symposium on HIV and Emerging Infectious Diseases

Marseille, France. 24-26 March 2010

\section{Background}

The AIDS Support Organization (TASO) started an ART program in 2004. With the increasing client load, it was inevitable that clinical care had to be shifted to the nurses. This study aimed at assessing the quality of clinical HIV care provided by nurses to TASO clients.

\section{Methods}

A cross-sectional survey employing qualitative and quantitative study designs was conducted at 4 purposively selected TASO sites. 400 exit interviews were conducted; 28 questionnaires administered to nurses, 56 clinical sessions observed; 51 medical charts reviewed and 4 key informant interviews conducted. Data was analyzed with the aid of Excel version 2000 and STATA version SE/10. Qualitative data was analyzed with the aid of Nvivo.

\section{Results}

About $92 \%$ of the clients expressed satisfaction with services received from TASO nurses. Peasant farmers were twice more likely to be satisfied with staff availability than the unemployed $(\mathrm{OR}=2.08 ; 95 \% \mathrm{CI}: 1.01-4.26$; $\mathrm{p}$-value $=$ $\left.0.046^{*}\right)$. Married clients were three times more likely to be satisfied with staff availability than the co-habiting (OR = 2.64; 95\%CI: $1.20-5.82$; p-value $\left.=0.016^{*}\right)$. Clients who had attained primary education were 1.5 times more likely to be satisfied with staff availability than the uneducated $(\mathrm{OR}=$ 1.52; 95\% CI: $0.91-2.55$; p-value $=0.113$ ). Nurses needed technical support to manage complex disease conditions. Fifty six percent of the nurses were able to write accurate ARV prescriptions. Key informants noted that comprehensive nurses had good clinical skills and positive attitudes.

\section{Discussion}

TASO Nurses exhibit positive attitudes. Comprehensive nurses have better clinical skills than the other nurse cadres. However, the overall nurses' technical competence as regards clinical HIV care provision requires improvement. They should be permitted to provide clinical care, under the supervision of a medical officer. They should be given protocols to follow during clinical sessions. Nursing schools should incorporate clinical HIV/AIDS care training into their curricula. Gender biases among clients should be addressed and a national dialogue on task shifting held.

\section{Author details}

${ }^{1}$ TASO, KAMPALA, Uganda. ${ }^{2}$ IDI, KAMPALA, Uganda.

Published: 11 May 2010

doi:10.1186/1742-4690-7-S1-P177

Cite this article as: Mugisha and Alex: Perceived quality of clinical Care provided by nurses to people living with HIV at Four TASO sites in Uganda. Retrovirology 2010 7(Suppl 1):P177.

Submit your next manuscript to BioMed Central and take full advantage of:

- Convenient online submission

- Thorough peer review

- No space constraints or color figure charges

- Immediate publication on acceptance

- Inclusion in PubMed, CAS, Scopus and Google Scholar

- Research which is freely available for redistribution

Submit your manuscript at www.biomedcentral.com/submit
BioMed Central 